\title{
INTERDISCIPLINARIDADE E EDUCAÇÃO AMBIENTAL: UM OLHAR SOBRE O DECLÍNIO DAS ABELHAS
}

\author{
Crisilandia de Nave da Silva ${ }^{1}$ \\ Roseli Adriana Blümke Feistel ${ }^{2}$ \\ Carmen Wobeto ${ }^{3}$ \\ Jean Reinildes Pinheiro ${ }^{4}$
}

Resumo: $O$ estudo apresenta uma análise de resultados de dissertações e artigos científicos, publicados em Bases de Dados das áreas de ensino de Ciências e Biomedicina no período de 2016 a 2020, acerca de pesquisas relacionadas ao ensino das radiações eletromagnéticas numa abordagem interdisciplinar. Em paralelo à investigação, buscou-se, ainda, trabalhos que discutiram a interação entre a radiação produzida pelos celulares, as estações de rádio base e as abelhas com vistas a compor uma transposição didática interdisciplinar, relacionando conceitos de eletromagnetismo e de Biologia. Trata-se de uma pesquisa de revisão de literatura, de natureza qualitativa e do tipo bibliográfico. Diante do estudo realizado, foi possível identificar que a abordagem da perspectiva interdisciplinar no ensino do Eletromagnetismo vem sendo pouco explorado no processo de ensino-aprendizagem de Física.

Palavras-chave: Educação Ambiental; Interdisciplinaridade; Radiações Eletromagnéticas Não lonizante; Polinizadores.

\footnotetext{
1Universidade Federal de Mato Grosso. E-mail: crisilandiasilva@gmail.com, Link para o Lattes: http://lattes.cnpq.br/1301974742595335.

2Universidade Federal de Mato Grosso. E-mail: roselifeistel@gmail.com, Link para o Lattes: http://lattes.cnpq.br/8516673002046226.

3Universidade Federal de Mato Grosso. E-mail: carmenwobeto2014@gmail.com, Link para o Lattes: http://lattes.cnpq.br/7629112688399234.

${ }^{4}$ Universidade Federal de Mato Grosso. E-mail: jeanpinheiro@gmail.com, Link para o Lattes: http://lattes.cnpq.br/4791706939726587.
} 
Abstract: The study presents an analysis of the results of dissertations and scientific articles, published in Databases of the teaching areas of Science and Biomedicine from 2016 to 2020, about research related to the teaching of electromagnetic radiation in an interdisciplinary approach. In parallel to the investigation, we also sought works that discussed the interaction between the radiation produced by cell phones, base radio stations and bees, with a view to composing an interdisciplinary didactic transposition, relating concepts of electromagnetism and biology. This is literature review research, qualitative in nature and bibliographic type. In view of the study carried out, it was possible to identify that the approach of the interdisciplinary perspective in the teaching of Electromagnetism has been little explored in the teaching-learning process of Physics.

Keywords: Environmental Education; Interdisciplinarity; Non-ionizing Electromagnetic Radiation; Pollinators.

\section{Introdução}

Vários ecossistemas do planeta estão passando por alterações significativas provocadas por ações do homem. Tais consequências da ação antrópica não podem ser ignorados pelo campo educacional. Assim sendo, considera-se necessário, incluir como tema transversal nos currículos escolares a Educação Ambiental (EA), haja visto que ela pode ser entendida como:

Um processo pelo qual o educando começa a obter conhecimentos acerca das questões ambientais, onde ele passa a ter uma nova visão sobre o meio ambiente, sendo um agente transformador em relação a conservação ambiental (MEDEIROS, et al., 2011, p. 2).

A inserção da EA nas escolas surge como uma ferramenta importante para fomentar discussão e problematizar questões socioambientais do meio social. Além disso, segundo Carvalho (2011), a EA:

Tem uma proposta ética de longo alcance que pretende reposicionar o ser humano no mundo, convocando-o a reconhecer a alteridade da natureza e a integridade e o direito à existência não utilitária do ambiente (CARVALHO, 2011, p. 151).

Pode-se considerar a EA nas escolas um caminho para sensibilizar e conscientizar os atores sociais, favorecendo uma abordagem crítica, ancorada em uma perspectiva contextualizada, interdisciplinar e transversal (RAMOS; 
VASCONCELOS, 2015), tendo como meta capacitá-los para a participação ativa e a solução de problemas ambientais.

Nesse contexto, o ensino de Física pautado na transversalidade da EA, pode contribuir para promover a formação de cidadãos críticos-reflexivos e a participação em debates acerca de questões socioambientais que prejudicam a qualidade de vida dos seres vivos, tendo em vista a interação de conhecimentos de diferentes áreas. Desse modo, oportuniza ao professor a introdução, em sala de aula, de temas controversos que envolvem questões éticas e de valores relacionadas ao desenvolvimento científico e tecnológico.

$\mathrm{Na}$ sociedade tecnologizada faz-se necessário buscar elementos para compreender e resolver problemas pertencentes ao contexto social. Para isso, a EA com sua dimensão interdisciplinar assume uma conotação relevante na educação ampliando as possibilidades de ensino e aprendizagem. $\mathrm{Na}$ concepção de Santana, Gama e Santos (2018, p. 217), a EA "pode proporcionar aos indivíduos embasamento teórico para uma reflexão sobre a sua condição real no ambiente ao qual está inserido". Assim sendo, foi escolhido o tema radiação eletromagnética não ionizante, produzida pelos celulares e linhas de transmissões de redes moveis e de tensão de alta energia, articulada ao declínio das abelhas. A presente discussão encontra-se inserida no cotidiano dos alunos, além disso apresenta caráter ambiental, social e ecológico vinculado aos avanços tecnológicos.

A polinização é apontada como um importante serviço ecossistêmico relacionado com a preservação da vida no planeta. As abelhas, de modo geral, são responsáveis pela polinização de cerca de $70 \%$ das plantas utilizadas na alimentação humana (FAO, 2004). As ações antrópicas no meio ambiente têm gerado consequências negativas e contribuído para o declínio de suas populações (IMPERATRIZ-FONSECA; NUNES-SILVA, 2010; MORAIS et al., 2018).

Nesta revisão são abordados alguns pressupostos teóricos sobre a interdisciplinaridade, a EA e um levantamento bibliográfico acerca dos estudos realizados com radiações eletromagnéticas e seus efeitos biológicos. Refere-se ao tema gerador de ensino e, mais especificamente, os efeitos de radiações eletromagnéticas não ionizantes sobre as abelhas, com vistas a fornecer suporte teórico para o ensino interdisciplinar de Física e Biologia, contextualizado por meio de questões ambientais.

\section{Interdisciplinaridade como viés da Educação Ambiental}

No Brasil, as discussões sobre a interdisciplinaridade foram introduzidas no final da década de 1970 por Hilton Japiassu. Considerado o precursor dos estudos acerca da interdisciplinaridade, tornou-se o primeiro pesquisador brasileiro a publicar uma obra expressiva sobre o tema em questão, intitulada "Interdisciplinaridade e Patologia do Saber" (JAPIASSU, 1976). Para o autor, a interdisciplinaridade se caracteriza pela intensidade na 
transferência de conhecimentos, na relação entre os professores e pelo grau de comunicação real entre as disciplinas envolvidas.

A interdisciplinaridade como abordagem teórico-metodológica contribui para a realização de trabalhos cooperativos no campo pedagógico, possibilitando a união de conhecimentos por meio da integração de diferentes áreas. Em vista disso, cabe ao professor, a realização da mediação das diversas fontes de conhecimentos. Contudo, a interdisciplinaridade não é simplesmente junção de disciplinas. Nessa direção, em conformidade com Fazenda (2011), desenvolver o ensino interdisciplinar constitui-se em uma atitude de buscar mudanças frente aos diversos conhecimentos, proporcionando um olhar sobre a natureza e oportunizando ao aluno uma maior compreensão dos fenômenos e fatos ecológicos, sociais, culturais e políticos.

No contexto do ensino interdisciplinar, Fazenda (2011, p. 12) pontua que "integração não pode ser pensada apenas no nível de integração de conteúdos ou métodos, mas basicamente no nível de integração de conhecimentos parciais, específicos, tendo em vista um conhecer global". Ainda, nessa perspectiva, Japiassu (1976, p. 75) esclarece que:

[...] a colaboração entre as diversas disciplinas ou entre os setores heterogêneos de uma mesma ciência conduz a interações propriamente ditas, isto é, a uma certa reciprocidade nos intercâmbios, de tal forma que, no final do processo interativo, cada disciplina saia enriquecida. [...] incorporar os resultados de várias especialidades, tomar de empréstimo a outras disciplinas certos instrumentos e técnicas metodológicas, fazendo uso dos esquemas conceituais e análises que se encontram nos diversos ramos do saber, a fim de fazê-los integrarem e convergirem, depois de terem sido comparados e julgados (JAPIASSU, 1976, p. 75).

No campo educacional, para qualquer discussão que tenha por objetivo utilizar a interdisciplinaridade como metodologia na abordagem de determinada problemática, preconiza-se uma reflexão sobre o significado de interdisciplinaridade analisando seus pressupostos e sua relação com o conhecimento a ser construído. Segundo Fazenda (2008), a prática interdisciplinar requer uma desconstrução, uma ruptura como o ensino tradicional.

As Diretrizes Curriculares Nacionais para Educação Básica (DCNEB) (BRASIL, 2013) enfatizam que deve partir da instituição escolar a organização dos currículos, pois entendem que a abordagem utilizada orienta as práticas pedagógicas dos professores e, consequentemente, revelam sua visão de mundo. De acordo com as DCNEB: 
A interdisciplinaridade pressupõe a transferência de métodos de uma disciplina para outra. Ultrapassa-as, mas sua finalidade inscreve-se no estudo disciplinar. Pela abordagem interdisciplinar ocorre a transversalidade do conhecimento constitutivo de diferentes disciplinas, por meio da ação didáticopedagógica mediada pela pedagogia dos projetos temáticos (BRASIL, 2013, p. 28).

A integração entre disciplinas, conhecimentos e conceitos favorecem a compreensão de forma mais significativa das temáticas trabalhadas na escola, pois possibilita a inserção do aluno na construção do seu próprio conhecimento em contato com diferentes formas de saberes. A interdisciplinaridade contribui para uma melhor compreensão dos problemas presentes no contexto social do aluno, como os problemas ambientais, por exemplo.

Nesse sentido, a interdisciplinaridade pode ser uma estratégia didática relevante para a superação da fragmentação do conhecimento. Na concepção de Matos (2016, p. 3), a interdisciplinaridade é "apontada como princípio da Educação Ambiental, pelo qual, poderia se observar a complexidade das questões ambientais de forma mais global".

As questões ambientais são bastante complexas e fazem parte do cotidiano do aluno. Logo, é necessário, uma abordagem global. Desse modo, a $\mathrm{AE}$ contribui para o desenvolvimento de uma compreensão integrada do meio ambiente em suas múltiplas e complexas relações, envolvendo aspectos ecológicos, psicológicos, legais, políticos, sociais, econômicos, científicos, culturais e éticos (BRASIL, 1999).

Vivemos em um mundo caracterizado pelos avanços científicos e tecnológicos. Tais avanços têm provocado mudanças expressivas no contexto atual, implicando em desafios para a sociedade que, por sua vez, precisam ser superados. As aplicações da Ciência e da Tecnologia têm gerado debates éticos em virtude dos efeitos provocados no ambiente, o que resulta na necessidade de os cidadãos estarem preparados para compreender a dinâmica social, indagando as reais intenções destas tecnologias.

Diante dos inúmeros problemas ambientais existentes no mundo, fazse necessário a abordagem da EA nas escolas de modo a possibilitar que as novas gerações tenham em seus currículos escolares discussões acerca da dimensão ambiental. Objetivando, assim, capacitar os cidadãos "para participação ativa na defesa do meio ambiente" (BRASIL, Art. 201981).

$\mathrm{Na}$ concepção de Gomes (2014, p. 7), a "Educação Ambiental como tema transversal, propõe um trabalho interdisciplinar, na qual todas as áreas do conhecimento sejam interligadas neste processo". E, sendo a escola um espaço de socialização, de troca de saberes, configura-se então, como um local importante para desenvolver o senso crítico dos alunos em relação às problemáticas ambientais, visando a sensibilização e a participação na busca por soluções. 
Deste modo, enfatiza-se que as noções, os objetivos, as habilidades e técnicas da interdisciplinaridade, como viés da EA, visam o desenvolvimento do processo de ensino-aprendizagem do ensino de Física por meio da integração de conhecimentos de diferentes áreas, na busca por novos saberes, novos olhares, novas indagações. No que concerne à prática educativa, implica em uma reflexão desde a ação docente até a organização das disciplinas, do currículo e da escola.

\section{Aspectos metodológicos da pesquisa}

Considerando o aumento acelerado do fluxo de informações científicas, a revisão de literatura é de grande importância na orientação do desenvolvimento de novos trabalhos, identificando as pesquisas já realizadas, os métodos já utilizados e as presentes lacunas a serem preenchidas por pesquisas posteriores.

O presente artigo trata de uma pesquisa de natureza qualitativa, do tipo bibliográfico de revisão de literatura. Tem por objetivo identificar as produções científicas desenvolvidas sobre o tema de ensino do Eletromagnetismo de forma interdisciplinar e os possíveis efeitos da radiação nas abelhas. A coleta foi realizada por meio de consulta em Bases de Dados eletrônicas, a saber: Google Acadêmico, Portal de Periódicos da Coordenação de Aperfeiçoamento de Pessoal de Nível Superior (CAPES) e PubMed. A pesquisa abrangeu artigos científicos e dissertações no período de 2016 a 2020.

Segundo Gil (2002, p. 44), pesquisa bibliográfica é aquela "desenvolvida com base em material já elaborado, constituído principalmente de livros e artigos científicos". Assim, este tipo de pesquisa possibilita a análise das diferentes compreensões acerca de um dado problema em diversos cenários. No que tange à fonte utilizada nessa pesquisa, as publicações periódicas são aquelas que apresentam assuntos diferentes, embora possuam um ou mais objetivos definidos.

Nesta revisão sistemática, buscou-se por meio de investigação, analisar e compreender o desenvolvimento de pesquisas referentes ao ensino das radiações eletromagnéticas na perspectiva interdisciplinar no Ensino Médio e as correlações entre a radiação eletromagnética produzidas pelos aparelhos celulares e torres de telefones e suas interações com as abelhas.

Com o intuito de selecionar os trabalhos que abordassem o Eletromagnetismo sob uma perspectiva interdisciplinar no ensino de Física no Ensino Médio, realizou-se a busca por pesquisas utilizando-se as palavraschave "interdisciplinaridade", "interdisciplinar", "Ensino Médio", "ensino de Física", "Eletromagnetismo" e "radiação". Tais termos foram pesquisados no título, nas palavras-chave e/ou no resumo de cada estudo encontrado. Com base na investigação realizada, foram encontradas 254 (duzentos e cinquenta e quatro) produções, no entanto, apenas 3 (três) estudos foram selecionados por abordarem o ensino do Eletromagnetismo de forma interdisciplinar. 
Para investigar o desenvolvimento de pesquisas relacionadas aos efeitos da radiação eletromagnética não ionizante produzidas pelas linhas de transmissão de telefones e aparelhos celulares nas abelhas foram usadas as palavras-chave "radiação eletromagnética", "telefone celular", "declínio dos polinizadores" e "abelhas". Dos 220 (duzentos e vinte) trabalhos encontrados, foram selecionadas somente 7 (sete) pesquisas pertinentes a temática em estudo. Vale ressaltar que, para seleção das investigações, foram consideradas apenas pesquisas científicas dos últimos 5 (cinco) anos disponíveis na Língua Portuguesa e Inglesa. Ao realizar a pesquisa nas Bases de Dados, as palavras-chave foram utilizadas entre aspas com a finalidade de restringir os resultados aos descritores específicos.

O Quadro 1, apresenta a distribuição dos trabalhos selecionados que abordam a temática do presente estudo, publicados em Bases de Dados nos últimos 5 (cinco) anos.

Quadro 1: Quantidade de trabalhos encontrados/selecionados em Bases de Dados nos últimos 5 (cinco) anos.

\begin{tabular}{|l|c|c|c|c|}
\hline \multirow{2}{*}{ Base de Dados } & \multicolumn{3}{|c|}{ № de trabalhos encontrados } & \multicolumn{2}{l|}{ № de trabalhos selecionados } \\
\cline { 2 - 5 } & IEEEM* & EREA $^{* *}$ & IEEEM & EREA \\
\hline Google Acadêmico & 249 & 87 & 3 & 5 \\
\hline Periódicos CAPES & 5 & 116 & 0 & 1 \\
\hline PubMed & - & 17 & - & 1 \\
\hline Total de trabalhos & 254 & 220 & 3 & 7 \\
\hline
\end{tabular}

* IEEEM = Interdisciplinaridade no Ensino do Eletromagnetismo no Ensino Médio.

${ }^{* *} \mathrm{EREA}=$ Efeito da Radiação Eletromagnética nas Abelhas.

Fonte: Elaborado pelos autores.

Após selecionar as produções científicas, realizou-se uma leitura detalhada dos trabalhos e, na sequência, para a análise qualitativa, buscou-se a compreensão dos autores acerca da temática, da metodologia utilizada, dos objetivos e dos principais resultados. A análise qualitativa dos estudos selecionados permitiu investigar e discutir acerca das produções científicas relacionadas à radiação eletromagnética e o ensino interdisciplinar e a interação com as abelhas.

\section{Interdisciplinaridade no ensino do Eletromagnetismo}

Com relação às discussões sobre a interdisciplinaridade no ensino do Eletromagnetismo foram encontrados 3 (três) trabalhos, sob forma de dissertação, na Base de Dados do Google Acadêmico.

Para uma melhor compreensão a respeito das produções científicas selecionadas, organizou-se o Quadro 2 com algumas informações das Dissertações, a saber: ano, título do trabalho, autoria, nível de ensino e metodologia desenvolvida nos estudos. 
Quadro 2: Dissertações abordando o Eletromagnetismo como tema interdisciplinar selecionadas na Base de Dados "Google Acadêmico".

\begin{tabular}{|c|c|c|c|c|}
\hline Ano & Título & Autor & $\begin{array}{l}\text { Nível de } \\
\text { ensino }\end{array}$ & Metodologia \\
\hline 2017 & $\begin{array}{l}\text { O ensino da interação radiação- } \\
\text { corpo humano nos anos iniciais do } \\
\text { Ensino Fundamental: uma } \\
\text { abordagem investigativa e } \\
\text { colaborativa com enfoque Ciência, } \\
\text { Tecnologia e Sociedade. }\end{array}$ & $\begin{array}{l}\text { Leandro da } \\
\text { Silva Barcellos }\end{array}$ & $\begin{array}{l}\text { Ensino } \\
\text { Fundamental }\end{array}$ & Qualitativa \\
\hline 2017 & $\begin{array}{l}\text { Radiação Ultravioleta: inserção de } \\
\text { Física Moderna no Ensino Médio } \\
\text { por meio dos efeitos biológicos da } \\
\text { radiação UV. }\end{array}$ & $\begin{array}{l}\text { Wellington } \\
\text { Clayton Silva }\end{array}$ & $\begin{array}{l}\text { Ensino } \\
\text { Superior }\end{array}$ & $\begin{array}{l}\text { Qualitativa e } \\
\text { Quantitativa }\end{array}$ \\
\hline 2019 & $\begin{array}{l}\text { Comunidades investigativas no } \\
\text { Ensino de Física: uma abordagem } \\
\text { interdisciplinar da radiação do } \\
\text { corpo negro. }\end{array}$ & $\begin{array}{c}\text { Daniel } \\
\text { Sampaio } \\
\text { Nunes }\end{array}$ & Ensino Médio & Qualitativa \\
\hline
\end{tabular}

Fonte: Elaborado pelos autores.

A dissertação de Barcellos (2017) apresentou uma proposta para o ensino da radiação ultravioleta (UV) e os efeitos no corpo humano. No decorrer da proposta, o autor debate com os alunos as consequências provocadas pela exposição prolongada aos raios UV destacando os efeitos nas células humanas e salientando a importância da prevenção para amenizar a interação desses raios no corpo humano.

Segundo Barcellos (2017, p. 115), a "abordagem interdisciplinar pode surgir por meio da colaboração entre diferentes professores especialistas envolvidos em um mesmo projeto". Nesse contexto, o autor destaca a realização de uma pesquisa colaborativa com profissionais das áreas de Física, Biologia e Pedagogia, haja vista a importância das diversas formações para a potencialização das trocas de experiências e saberes. Além disso, enfatiza o caráter interdisciplinar e sociocientífico do trabalho, utilizando os pressupostos do enfoque Ciência-Tecnologia-Sociedade (CTS).

O trabalho de Silva (2017) teve por objetivo a abordagem das radiações ultravioletas (UV). Para isso, o autor aplicou uma Sequência Didática interdisciplinar para graduandos do Ensino Superior, articulando os conteúdos das áreas de Física, Química e Biologia, com o intuito de contribuir para a abordagem de conteúdos relacionados à Física Moderna e à prática docente de professores das áreas citadas. O estudo fundamentou-se na Teoria da Aprendizagem Significativa de David Ausubel e na Aprendizagem Significativa Crítica de Moreira. Ainda, no mesmo estudo, Silva (2017) enfocou a importância do tema pela presença no cotidiano das pessoas, permitindo um entendimento mais global e significativo e pela integração deste com outras disciplinas. 
O estudo de Nunes (2019) apresentou o desenvolvimento de uma Sequência Didática, como Produto Educacional, fundamentada pela Teoria de Educação de Matthew Lipman e a Teoria da Aprendizagem Significativa de David Ausubel, na abordagem da radiação do corpo negro, com alunos do 3 o Ano do Ensino Médio. Em relação à perspectiva interdisciplinar, o autor trabalha conceitos que apresentam relações com a Matemática, a Química, a Filosofia, a História, a Sociologia, a Língua Portuguesa e a Medicina.

O autor justificou a importância de preparar o discente para debates que envolvam questões de caráter ético, criando situações em sala de aula para encorajar a criticidade, a reflexão e a participação autônoma frente às temáticas sociais. Segundo Nunes (2019), é papel do educador oportunizar aos seus educandos condições para a construção do pensamento investigativo, crítico e reflexivo.

Considerando as reflexões suscitadas em razão dos trabalhos analisados, é possível sinalizar que a inserção da interdisciplinaridade como metodologia pedagógica da ação docente é relevante no campo educacional, possibilitando o planejamento e a realização de pesquisas que envolvem diferentes áreas do conhecimento. Além disso, podem ser oportunizadas e/ou elaboradas situações de modo que os saberes se integrem, ampliando, assim, as fronteiras do conhecimento.

Contribuindo com as discussões, a Base Nacional Comum Curricular (BNCC) (BRASIL, 2017), em conformidade com os fundamentos teóricometodológicos que apresenta, propõe acerca da interdisciplinaridade:

[...] a superação da fragmentação radicalmente disciplinar do conhecimento, o estímulo à sua aplicação na vida real, a importância do contexto para dar sentido ao que se aprende e o protagonismo do estudante em sua aprendizagem e na construção de seu projeto de vida (BRASIL, 2017, p. 15).

É possível afirmar que os trabalhos analisados foram planejados e desenvolvidos com o intuito de contribuir com a prática interdisciplinar no ensino do Eletromagnetismo nas aulas de Física. Barcellos (2017), Silva (2017) e Nunes (2019) enfatizam a importância da interdisciplinaridade no processo de ensino-aprendizagem, destacando uma compreensão mais significativa pautada pela interação de conhecimentos de diferentes áreas.

Ao realizar a leitura das dissertações de Barcellos (2017) e Silva (2017), evidenciou-se a utilização da Teoria de Aprendizagem Significativa de Ausubel como aporte teórico no processo de aprendizagem no ensino de Física. Já, no trabalho de Nunes (2019), fez-se uso dos fundamentos da teoria sociocultural de Vygotsky para embasar a abordagem e as ferramentas analíticas. 
Os pressupostos do enfoque CTS foram inseridos como aliados na abordagem interdisciplinar do trabalho do Barcellos (2017), visto que a temática abordada apresenta uma relevância na sociedade, pois trata de questões relacionadas à saúde da população, à sensibilização para a prevenção do câncer de pele.

Entende-se que a perspectiva CTS no ensino de Física é relevante, pois permite a abordagem de temas que apresentam um caráter social que possui significado na vivência do aluno. Além disso, os pressupostos CTS visam um ensino reflexivo e contextualizado, com a intenção de capacitar cidadão críticos, que possam interagir com a sociedade (PINHEIRO; SILVEIRA; BAZZO, 2007).

Nos trabalhos analisados observou-se a ausência de estudos sobre o ensino da radiação eletromagnética produzida por aparatos tecnológicos, como também, não há menção dos possíveis efeitos biológicos causados nos insetos pela influência dos campos magnéticos. É necessário trabalhar a EA nesta temática, para que os estudantes possam compreender os possíveis efeitos da radiação artificial dos aparatos tecnológicos para os ecossistemas.

Nesse sentido, realizou-se um levantamento bibliográfico de estudos científicos que exploram os efeitos das radiações eletromagnéticas não ionizante na sobrevivência das abelhas. Este levantamento constitui-se em um conjunto de conhecimentos científicos, com potencial de ser usado como ferramenta para a produção de conhecimentos escolares, fomentar a discussão desta temática em sala de aula por professores de Física ou de outras disciplinas que anseiam desenvolver trabalhos de EA, mas não dispõem de material de apoio relacionado à temática em questão.

No âmbito escolar, considera-se relevante a abordagem dos possíveis efeitos da radiação eletromagnética não ionizante proveniente de torres de telefones e aparelhos celulares nas abelhas. Remetendo, assim, às discussões que considerem a transposição didática do conhecimento científico desta temática. Dada a importância, na sequência é apresentada a revisão bibliográfica de artigos científicos que enfatizam o debate acerca da interação entre a radiação dos celulares, as torres de telefonia e as abelhas.

\section{Interação entre a radiação dos celulares, as torres de telefonia e as abelhas}

As abelhas são importantes insetos presentes no ecossistema e consideradas os mais efetivos polinizadores bióticos (FAO, 2004; NUNESSILVA, 2010). A polinização realizada por esses insetos é considerada um serviço ecossistêmico responsável pela alta quantidade e qualidade dos frutos produzidos em diversas culturas utilizadas para a alimentação humana.

Os agentes polinizadores são elementos essenciais na realização de um processo ecológico vital para a sobrevivência humana. Por isso, a redução 
considerável da diversidade populacional das abelhas poderá causar impactos expressivos no meio ambiente (KERR et al., 2001).

Atualmente, em razão da disseminação de dispositivos móveis, o número de torres de telefone tem aumentado consideravelmente, causando poluição ambiental, expondo constantemente organismos vivos a Campos Eletromagnéticos (CEM). Essa questão tem gerado preocupações, a nível global, levando à debates sobre os efeitos adversos dos CEM à saúde.

Um fenômeno intrigante foi identificado e descrito em 2006 em colmeias de Apis mellifera L. (Hymenoptera, Apidae), nos Estados Unidos e Reino Unido, no qual as abelhas não retornam para a colmeia, deixando a rainha sem alimento e com a ninhada jovem. Este fenômeno foi chamado de Distúrbio do Colapso das Colônias (DCC) e foram apontados alguns fatores como desencadeadores deste distúrbio: doenças, inimigos naturais, pesticidas, desmatamento, condições climáticas adversas (FAVRE, 2011). Mais recentemente, há relatos científicos de que os CEM podem ser fatores a serem considerados no DCC (TAYE et al., 2017; ODEMER; ODEMER, 2019).

De acordo com o Quadro 3, no que tange às discussões acerca da interação entre a radiação dos celulares, as torres de telefonia e as abelhas, foram encontrados 7 (sete) trabalhos sob forma de artigos científicos, nas Bases de Dados do Google Acadêmico, Periódicos CAPES e PubMed.

Quadro 3: Bases de Dados e os respectivos trabalhos selecionados.

\begin{tabular}{|c|c|c|c|}
\hline \multirow{2}{*}{$\begin{array}{l}\text { Base de } \\
\text { Dados }\end{array}$} & \multicolumn{3}{|c|}{ Pesquisas selecionadas } \\
\hline & Autores & Título & Ano \\
\hline \multirow[t]{5}{*}{$\begin{array}{c}\text { Google } \\
\text { Acadêmico }\end{array}$} & $\begin{array}{l}\text { Erdoğan, Y.; } \\
\text { Cengiz, M. M. }\end{array}$ & $\begin{array}{l}\text { Effect of Electromagnetic Field (EMF) and } \\
\text { Electric Field (EF) on Some Behavior of } \\
\text { Honeybees (Apis mellifera L.). }\end{array}$ & 2019 \\
\hline & Patel, S.; Mall, P. & $\begin{array}{l}\text { Effect of electromagnetic radiations on the } \\
\text { foraging activity of Apis mellifera. } L \text {. }\end{array}$ & 2019 \\
\hline & Taye, R. R. et al. & $\begin{array}{l}\text { Effect of electromagnetic radiation of cell phone } \\
\text { tower on foraging behaviour of Asiatic honey } \\
\text { bee, Apis cerana F. (Hymenoptera: Apidae). }\end{array}$ & 2017 \\
\hline & $\begin{array}{l}\text { Wyszkowska, J.; } \\
\text { Grodzicki, P.; } \\
\text { Szczygieł, M. }\end{array}$ & $\begin{array}{l}\text { Electromagnetic fields and colony collapse } \\
\text { disorder of the honeybee. }\end{array}$ & 2019 \\
\hline & Zubrzak, B. et al. & $\begin{array}{l}\text { Thermal and acoustic changes in bee colony } \\
\text { due to exposure to microwave electromagnetic } \\
\text { field-preliminary research. }\end{array}$ & 2018 \\
\hline $\begin{array}{l}\text { Periódicos } \\
\text { CAPES }\end{array}$ & $\begin{array}{l}\text { Odemer, R.; } \\
\text { Odemer, F. }\end{array}$ & $\begin{array}{l}\text { Effects of radiofrequency electromagnetic } \\
\text { radiation (RF-EMF) on honey bee queen } \\
\text { development and mating success. }\end{array}$ & 2019 \\
\hline PubMed & $\begin{array}{l}\text { Shepherd, S. et } \\
\text { al. }\end{array}$ & $\begin{array}{l}\text { Extremely Low Frequency Eletromagnetic Fields } \\
\text { impar the Cognitive and Motor Abilities of Honey } \\
\text { Bees. }\end{array}$ & 2018 \\
\hline
\end{tabular}

Fonte: Elaborado pelos autores. 
Não existem muitos estudos que investigaram a influência da radiação nas abelhas. Entretanto, nas últimas décadas, a maioria das pesquisas realizadas, vêm sinalizando as consequências dos campos eletromagnéticos no ecossistema. Todavia, não há consenso entre os pesquisadores sobre os efeitos acerca das abelhas (KUMAR, 2018; PATEL; MALL, 2019; ODEMER; ODEMER, 2019).

Alguns estudos como Taye et al. (2017), Shepherd et al. (2018), Patel e Mall (2019) e Odemer e Odemer (2019) analisaram os efeitos biológicos dos CEM gerados por celulares e torres de telefonia na sobrevivência das abelhas.

Em relação aos trabalhos sobre os efeitos da radiação eletromagnética nas abelhas, encontramos apenas o estudo de Shepherd et al. (2018) envolvendo a participação de pesquisadores brasileiros, o que mostra a necessidade do desenvolvimento de um número maior de pesquisas relacionadas à essa temática em nosso país. A emissão de radiação eletromagnética não ionizante de aparelhos e torres de celulares no ambiente precisa ser considerada como um problema sério, pois remete à inúmeras implicações socioambientais, o qual requer, ainda, muita pesquisa para a compreensão real dos possíveis riscos.

Na sequência, apresenta-se no Quadro 4 as pesquisas desenvolvidas que investigaram os possíveis efeitos biológicos da exposição das abelhas às radiações eletromagnéticas não ionizantes advindas de torres e telefonia móvel.

Quadro 4: Pesquisas desenvolvidas experimentalmente sobre os efeitos causados por campos eletromagnéticos em abelhas.

\begin{tabular}{|c|c|c|c|l|}
\hline Autores/Ano & Frequência & $\begin{array}{c}\text { Duração do } \\
\text { experimento }\end{array}$ & $\begin{array}{c}\text { Fonte } \\
\text { emissora }\end{array}$ & Considerações \\
\hline $\begin{array}{c}\text { Taye et al. } \\
(2017)\end{array}$ & $900 \mathrm{MHZ}$ & 5 meses & $\begin{array}{c}\text { Torre de } \\
\text { celular }\end{array}$ & $\begin{array}{l}\text { Alterações na atividade de voo e } \\
\text { capacidade de retorno. }\end{array}$ \\
\hline $\begin{array}{c}\text { Patel; Mall } \\
(2019)\end{array}$ & $900 \mathrm{MHz}$ & 15 dias & $\begin{array}{c}\text { Torre de } \\
\text { celular }\end{array}$ & $\begin{array}{l}\text { Não foram registradas } \\
\text { alterações significativas na } \\
\text { atividade de forrageamento. }\end{array}$ \\
\hline $\begin{array}{c}\text { Shepherd et al. } \\
(2018)\end{array}$ & $50 \mathrm{~Hz}$ & 1 dia & Bobinas & $\begin{array}{l}\text { Alterações nas habilidades } \\
\text { cognitivas, motoras, diminuição } \\
\text { de aprendizagem olfativo, } \\
\text { redução na busca por alimentos. }\end{array}$ \\
\hline $\begin{array}{c}\text { Zubrzak et al. } \\
(2018)\end{array}$ & $900 \mathrm{MHz}$ & 4 dias & $\begin{array}{c}\text { Sinal } \\
\text { modulado } \\
\text { +antena }\end{array}$ & $\begin{array}{l}\text { Não foram registradas } \\
\text { alterações quanto a temperatura } \\
\text { e a acústica. }\end{array}$ \\
\hline $\begin{array}{c}\text { Wyszkowska; } \\
\text { Grodzicki; } \\
\text { Szczygieł } \\
\text { (2019) }\end{array}$ & $50 \mathrm{~Hz}$ & 1 dia & Bobina & $\begin{array}{l}\text { Não verificaram aumento } \\
\text { expressivo na taxa de } \\
\text { mortalidade, nem na capacidade } \\
\text { locomotora das abelhas. }\end{array}$ \\
\hline $\begin{array}{c}\text { Odemer; } \\
\text { Odemer (2019) }\end{array}$ & $900 \mathrm{MHz}$ & 25 dias & Celular & $\begin{array}{l}\text { Diminuição significativa da } \\
\text { pupação. }\end{array}$ \\
\hline $\begin{array}{c}\text { Erdoğan; } \\
\text { Cengiz (2019) }\end{array}$ & $50 \mathrm{~Hz} \mathrm{CA}$ & 15 dias & $\begin{array}{c}\text { Bobinas } \\
\text { Helmholtz }\end{array}$ & $\begin{array}{l}\text { A atividade de forrageamento } \\
\text { foram afetadas. }\end{array}$ \\
\hline \multicolumn{2}{|c|}{} & & &
\end{tabular}

Fonte: Elaborado pelos autores. 
Zubrzak et al. (2018) constataram que a $900 \mathrm{MHZ}$ (Quadro 4), não houve mudanças significativas de temperatura durante ou após a exposição dos CEM na colmeia (Apis mellifera carnica) exposta, quando comparada com a colmeia controle, e que os sinais acústicos das colmeias não foram afetados por campos elétricos de $7 \mathrm{~V} / \mathrm{m}$.

Nessa mesma frequência, Odemer e Odemer (2019) não identificaram alterações quanto ao acasalamento da abelha rainha, nem quanto à sobrevivência desta na fase larval exposta à radiação do telefone celular, durante todo o período de incubação até a fase pré adulto. Entretanto, registraram um aumento da mortalidade de pupas das abelhas rainhas. É importante ressaltar que, nesse caso, o celular estava a poucos centímetros de distância da colmeia.

Quanto aos efeitos biológicos da radiação eletromagnética não ionizante observados em outros seres vivos, Okuno e Yoshimura (2010) contribuem com as discussões acerca do assunto. Os autores destacaram que a profundidade de penetração das ondas eletromagnéticas de telefonia celular em torno de $900 \mathrm{MHZ}$ podem atingir $3,0 \mathrm{~cm}$ de profundidade em um tecido, que apresenta um elevado conteúdo de água, como o tecido muscular.

Okuno e Yoshimura (2010) salientaram que o tempo de exposição, a frequência, a intensidade do campo e a espessura do tecido são variáveis que determinam o aquecimento interno do tecido, o qual as vezes não pode ser compensado pelo organismo, o que acaba por ocasionar os efeitos biológicos.

Segundo Patel e Mall (2019), em 5 meses de avaliação, observaram que a colmeia de Apis mellifera L., exposta a $900 \mathrm{MHZ}$ abaixo da torre de celular não apresentou alterações na atividade de forrageamento sob a influência de campo elétrico que variou de $255-545,8 \mathrm{mV} / \mathrm{m}$. Porém, Taye et al. (2017) em uma avaliação de 15 dias, registraram que o número de abelhas que retornaram para a colmeia declinou em colônias de Apis cerana F. posicionadas mais próximas das torres em comparação com colônias mais distantes. A média de abelhas que retornaram por minutos na colônia posicionada a $500 \mathrm{~m}$ da torre foi de 33,29 abelhas e na colônia a $100 \mathrm{~m}$ foi de 28,58 abelhas. A colmeia mais afetada estava a $100 \mathrm{~m}$ e a intensidade do campo elétrico oscilou de 159 a $189 \mathrm{mV} / \mathrm{m}$. Enquanto, a colmeia menos afetada estava a $500 \mathrm{~m}$ da torre e a intensidade do campo elétrico variou de 63 a $101 \mathrm{mV} / \mathrm{m}$. Contudo, não foram observadas alterações significativas quanto ao número de abelhas que retornaram com cargas de pólen. Os autores concluíram que, o forrageamento e o comportamento podem ter sido afetados devido à radiação da torre de telefone, e mencionaram que a exposição a radiações a longo prazo poderia interferir na saúde das abelhas.

Nos estudos de Patel e Mall (2019) e Taye et al. (2017) algumas variáveis foram diferentes: o tempo de avaliação, as espécies de abelhas, a distância das colmeias até a fonte emissora de radiação. Comparando esses estudos verificou-se que a intensidade dos campos elétricos foi diferente em 
razão das variações nas distâncias entre as colmeias e fonte emissora, assim como os efeitos biológicos possivelmente estão relacionados a um maior tempo de exposição à radiação e as diferenças genéticas entre as espécies avaliadas, ou seja, uma espécie poderia ser mais suscetível do que outra. Estes fatores podem justificar as divergências nas conclusões.

Em suas investigações, Wyszkowska, Grodzicki e Szczygieł (2019) avaliaram a locomoção das abelhas (Apis mellifera carnica F.) por 1 dia, sob a influência de CEM a $50 \mathrm{~Hz}$, gerados por uma bobina à $1 \mathrm{~m}$ de distância e observaram que a capacidade locomotora das abelhas expostas a intensidades de $1 \mathrm{mT}$ e $7 \mathrm{mT}$ não sofreram alterações significativas. No entanto, constatouse uma ligeira alteração na atividade para grupos expostos a $7 \mathrm{mT}$. Os autores descreveram ainda, que não houve mortalidade expressiva das abelhas, mas verificaram que apesar do grupo exposto a $7 \mathrm{mT}$ apresentar mais mortalidade do que a $1 \mathrm{mT}$, estas diferenças não foram significativas. Por fim, finalizam a pesquisa salientando que a influência do CEM depende da dose de exposição.

Estes resultados são divergentes às conclusões relatadas por Erdoğan e Cengiz (2019), em que nessa mesma faixa de frequência de radiação, observaram que o tempo de permanência e o número de abelhas (Apis mellifera L.) que visitavam as bobinas, durante a atividade de forrageamento, foram alterados onde o campo elétrico e o campo magnético possuíam intensidades maiores. Neste estudo foram usadas cinco bobinas configuradas em níveis diferentes de campos elétrico e magnético, as quais foram colocadas placas de petry contendo xarope de açúcar. Os autores observaram que a placa menos visitada estava em campo magnético $(200 \mu \mathrm{T})$ e elétrico (264 $\mathrm{mV} / \mathrm{m}$ ) de maior intensidade, cujo tempo de permanência das abelhas foi de 12,61s. Já nos campos de menor intensidade $(0 \mu \mathrm{T}$ e $90 \mathrm{mV} / \mathrm{m})$, o tempo médio de permanência foi de 37,88s. As bobinas estavam posicionadas a 100 $\mathrm{m}$ de distância das colônias das abelhas. O tempo de avaliação foi de 15 dias e, possivelmente, esta variável tenha afetado as conclusões divergentes comparando-se com o trabalho de Wyszkowska, Grodzicki e Szczygieł (2019), uma vez que estes avaliaram apenas por 24 horas.

Shepherd et al. (2018) verificaram que abelhas expostas a CEM de 20 $\mu \mathrm{T}$ apresentaram menor aprendizado quando comparado à colmeia controle (sem exposição CEM). Entretanto, obtiveram uma maior aquisição de aprendizagem quando comparado a abelhas expostas aos CEM de maiores intensidades testados (100 $\mu \mathrm{T}$ e $1000 \mu \mathrm{T})$. Além disso, durante o voo das abelhas, observaram que houve aumento significativo da frequência de batidas das asas devido ao aumento da intensidade do CEM, sendo mais pronunciado nos campos de $100 \mu \mathrm{T}$ e $1000 \mu \mathrm{T}$. Também investigaram o efeito da exposição das abelhas a CEM de $100 \mu \mathrm{T}$ na atividade de busca de alimento e verificaram a redução desta atividade quando comparado com a colmeia controle.

Observam-se divergências entre alguns resultados apresentados. Nesse contexto, Kumar (2018) salienta a necessidade da utilização de parâmetros e de metodologia de medição mais clara e definida, de rigorosidade 
na coleta e análise dos dados durante os experimentos. Tendo em vista que a produção de trabalhos científicos exige um conjunto de elementos coerentes com os objetivos a serem atingidos.

Embora os estudos apresentem objetivos diferentes, pode-se observar que a maioria sinalizou a radiação eletromagnética não ionizante, da telefonia móvel e dos aparelhos celulares, como uma das possíveis causas para o agravamento do declínio dos polinizadores. Em vista disso, mais estudos precisam ser viabilizados, a fim de obter dados que contribuam para conclusões mais precisas sobre os efeitos a longo prazo, assim como envolver espécies de abelhas nativas de biomas brasileiros e de outras regiões tropicais e subtropicais.

\section{Considerações finais}

Para o ensino-aprendizagem da Física necessita-se de uma prática que seja capaz de tornar este processo mais dinâmico e significativo para 0 aluno, para além da simples transmissão descontextualizada e fragmentada de conteúdos distantes da realidade do estudante. Dessa maneira, a EA como tema transversal contribui para a abordagem de problemas reais, existentes no ambiente em que o aluno está inserido.

A interdisciplinaridade é apontada em documentos oficiais, na BNCC (BRASIL, 2017), nos PCNEM (BRASIL, 2000) e nas DCNEB (BRASIL, 2013), como uma prática que pode contribuir para a superação do tratamento estanque e fragmentado do ensino, pois possibilita a contextualização, a integração e a religação dos conhecimentos abordados.

No que concerne à interdisciplinaridade no ensino do Eletromagnetismo de forma articulada com os efeitos biológicos em discussões envolvendo as abelhas, não foram encontradas produções de conhecimentos no campo educacional. Mesmo sendo um tema rico e propício à EA e à interdisciplinaridade por meio da interação com outras áreas do conhecimento, observa-se uma escassez de materiais que poderiam ser utilizados em sala de aula.

Nesse sentido, a revisão bibliográfica realizada sobre os efeitos da radiação eletromagnética não ionizante nas abelhas constituiu-se em um apanhado de conhecimentos pertencentes ao saber sábio. Este saber refere-se àquele produzido a partir da pesquisa acadêmica, e que pode ser transformado em saber ensinado, caracterizando-se por uma linguagem mais acessível (CHEVALLARD, 2013).

Nesta perspectiva, entende-se a necessidade de produzir e disponibilizar material de apoio aos professores para a abordagem desta temática no contexto da transversalidade da EA. Portanto, o levantamento bibliográfico realizado neste estudo constitui-se em uma compilação de dados científico com uso potencial em sala de aula. 
Nessa mesma vertente, pode-se observar ainda, por meio desta pesquisa que, no campo educacional, o desenvolvimento de trabalhos que abordam a radiação não ionizante (de aparatos tecnológicos) de forma interdisciplinar, voltado à sala de aula, ainda é escasso. A prática interdisciplinar no ensino do Eletromagnetismo contribui para que o aluno relacione os conhecimentos construídos com situações de sua vivência. Desta forma, o enfoque da questão ambiental no ensino de Física favorece a formação de cidadãos aptos para analisar os benefícios e os malefícios do uso das tecnologias presentes no cotidiano.

A abordagem interdisciplinar no ensino do Eletromagnetismo articulado ao declínio das abelhas, permite integrar conhecimentos de Física e Biologia. É possível, assim, explorar os conceitos eletromagnéticos e o papel ecológico das abelhas para o equilíbrio da natureza e, com isso, a responsabilidade do homem para com a preservação dos principais polinizadores do planeta.

\section{Referências}

BARCELLOS, L. S. O ensino da interação radiação-corpo humano nos anos iniciais do Ensino Fundamental: uma abordagem investigativa e colaborativa com enfoque Ciência, Tecnologia e Sociedade. 2017. Dissertação (Mestrado em Ensino de Física) - Centro de Ciências Exatas, UFES, Vitória, 2017.

BRASIL. Lei № 6.938, de 31 de agosto de 1981. Dispõe sobre a Política Nacional do Meio Ambiente, seus fins e mecanismos de formulação e aplicação, e dá outras providências. Disponível em: $<$ http://www.planalto.gov.br/ccivil 03/leis/l6938compilada.htm>. Acesso: 29 jun. 2020.

BRASIL. Lei № 9.795, de 27 de abril de 1999. Dispõe sobre a Educação Ambiental, institui a Política Nacional de Educação Ambiental e dá outras providências. Disponível em: $<$ http://www.planalto.gov.br/ccivil 03/leis/19795.htm>. Acesso: 29 jun. 2020.

BRASIL. Diretrizes Curriculares Nacionais para Educação Básica. Brasília: MEC/SEB; DICEI, 2013. Disponível em: <http://portal.mec.gov.br/docman/julho2013-pdf/13677-diretrizes-educacao-basica-2013-pdf/file>. Acesso: 30 jun. 2020.

BRASIL. Parâmetros Curriculares Nacionais para o Ensino Médio. Bases Legais. Brasília: MEC/SEB. 2000. Disponível em: $<$ http://portal.mec.gov.br/seb/arquivos/pdf/blegais.pdf>. Acesso: 30 jun. 2020.

BRASIL. Base Nacional Comum Curricular. Brasília: MEC/CONSED/UNDIME, 2017. Disponível em: $<$ http://basenacionalcomum.mec.gov.br/images/BNCC 20dez site.pdf>. Acesso: 30 jun. 2020.

CARVALHO, I. C. M. Educação Ambiental: a formação do sujeito ecológico. 5. ed. São Paulo: Cortez, 2011. 
CHEVALLARD, Y. Sobre a teoria da transposição didática: algumas considerações introdutórias. Revista de Educação, Ciências e Matemática, v. 3, n. 2, 2013.

ERDOĞAN, Y.; CENGIZ, M. M. Effect of Electromagnetic Field (EMF) and Electric Field (EF) on Some Behavior of Honeybees (Apis mellifera L.). bioRxiv, [s.l], p. 1-18, abr. 2019.

FAO. Food and Agricultural Organization. Conservation and management of pollinators for sustainable agriculture - the international response. In: FREITAS, B. M.; PEREIRA, J. O. P. (eds.) Solitary bees: conservation, rearing and management for pollination. Imprensa Universitária. Fortaleza, Brasil. p. 19-25, 2004.

FAVRE, D. Mobile phone-induced honeybee worker piping. Apidologie, Alemanha, v. 42, n, 3, p. 270-279, abr. 2011.

FAZENDA, I. C. A. Integração e interdisciplinaridade no ensino brasileiro: efetividade ou ideologia. São Paulo: Loyola, 2011, 176 p.

FAZENDA, I. C. A. A aquisição de uma formação interdisciplinar de professores. In: FAZENDA, I. C. (org.). Didática e Interdisciplinaridade. 13. ed. Campinas: Papirus, 2008. p. 11-20.

FERREIRA, N. S. A. As pesquisas denominadas "estado da arte". Educação \& Sociedade, Campinas, v. 23, n. 79, p. 257-272, ago. 2002.

GIL, A. C. Como elaborar projetos de pesquisa. 4. ed. São Paulo: Atlas, $2002.176 \mathrm{p}$.

GOMES, R. W. Por uma Educação Ambiental crítica/emancipatória: dialogando com alunos de uma escola privada no município de Rio Grande/RS. Ciência e Natura - Revista do Centro de Ciências Naturais e Exatas, Santa Maria, v. 36, n. 3, p 430-440, set./dez. 2014.

IMPERATRIZ-FONSECA, V. L.; NUNES-SILVA, P. As abelhas, os serviços ecossistêmicos e o Código Florestal Brasileiro. Biota Neotropical, v. 10, n. 4, p. 59-62, 2010.

JAPIASSU, H. Interdisciplinaridade e patologia do saber. Rio de Janeiro: Imago, 1976. 111p.

KERR, W. E. et al. Aspectos pouco mencionados da biodiversidade amazônica. Parcerias Estratégicas, Brasília, v. 6, n. 12, p. 20-41, set. 2001.

KUMAR, S. S. Colony Collapse Disorder (CCD) in Honey Bees Caused by EMF Radiation. Bioinformation, [s.I], v. 14, n. 9, p. 421-424, dez. 2018.

MATOS, F. F. A interdisciplinaridade como objeto da Educação Ambiental: uma análise da produção científica da área. Revista Brasileira de Educação Ambiental, São Paulo, v. 11, n. 2, p. 178-191, 2016.

MEDEIROS, A. B. et al. A importância da Educação Ambiental na escola nas series iniciais. Revista Faculdade Montes Belos, v. 4, n. 1, set. 2011. 
MORAIS, C. R. et al. Ecotoxicological effects of the insecticide fipronil in Brazilian native stingless bees Melipona scutellaris (Apidae: Meliponini). Chemosphere, v. 206, p. 632-642, 2018.

NUNES, D. S. Comunidades investigativas no Ensino de Física: uma abordagem interdisciplinar da radiação do corpo negro. 2019. Dissertação (Mestrado em Ensino de Física) - Instituto de Física, UNB, Brasília, 2019.

ODEMER, R.; ODEMER, F. Effects of radiofrequency electromagnetic radiation (RF-EMF) on honey bee queen development and mating success. Science of The Total Environment, [s.I], v. 661, p. 553-562, abr. 2019.

OKUNO, E.; YOSHIMURA, E. M. Física das radiações. São Paulo: Oficina de Textos, 2010. $296 \mathrm{p}$.

PATEL, S.; MALL, P. Effect of electromagnetic radiations on the foraging activity of Apis mellifera L. Journal of Experimental Zoology, India, v. 22, n. 1, p. 449-451, 2019.

PINHEIRO, N. A. M.; SILVEIRA, R. M. C. F.; BAZZO, W. A. Ciência, Tecnologia e Sociedade: a relevância do enfoque CTS para o contexto do Ensino Médio. Ciência \& Educação, Bauru, v. 13, n. 1, p. 71-84, abr. 2007.

RAMOS, I. L; VASCONCELOS, T. N. H. Prática pedagógica a partir da aplicação de atividades contextualizadas sobre o tratamento de água no ensino de Química e Educação Ambiental. Revista de Ensino de Ciências e Matemática, v. 6, n. 3, p. 72-90, 2015.

SANTANA. G. R. A; GAMA, J. A. S; SANTOS, E. B. Análise da inserção da Educação Ambiental nas escolas estaduais da região central da Área de Proteção Ambiental Costa dos Corais (AL). Revista Brasileira de Educação Ambiental, v. 13, n. 4, p. 216-227, 2018.

SHEPHERD, S. et al. Extremely Low Frequency Eletromagnetic Fields impar the Cognitive and Motor Abilities of Honey Bees. Scientific reports, [s.I], v. 8, n. 7932, p. 1-9, maio 2018.

SILVA, W. C. Radiação ultravioleta: inserção de Física Moderna no Ensino Médio por meio de efeitos biológicos da radiação UV. 2017. 142 f. Dissertação (Mestrado em Ensino de Ciências) - Instituto de Ciências Exatas e Biológicas, UFOP, Ouro Preto, 2017.

TAYE, R. R. et al. Effect of electromagnetic radiation of cell phone tower on foraging behaviour of Asiatic honey bee, Apis cerana F. (Hymenoptera: Apidae). Journal of Entomology and Zoology Studies, v. 5, n. 3, p. 15271529, abr. 2017.

WYSZKOWSKA, J.; GRODZICKI, P; SZCZYGIEK, M. Electromagnetic fields and colony collapse disorder of the honeybee. Przegląd Elektrotechniczny, [s.I], v. 95, p. 137-140, jan. 2019.

ZUBRZAK, B. et al. Thermal and acoustic changes in bee colony due to exposure to microwave electromagnetic field-preliminary research. Przegląd Elektrotechniczny, [s.I], v. 94, p. 262-265, dez. 2018. 